\title{
Development and Testing of an Electrochemical Methane Sensor
}

\author{
Praveen K. Sekhar ${ }^{1}$, Jesse Kysar ${ }^{1}$, Eric L. Brosha ${ }^{2}$, and Cortney R. Kreller ${ }^{2}$ \\ ${ }^{1}$ Nanomaterials and Sensors Laboratory, School of Engineering and Computer Science, \\ Washington State University, Vancouver, WA 98686, USA. \\ ${ }^{2}$ Materials, Synthesis and Integrated Devices Group, Los Alamos National Laboratory, Los \\ Alamos, NM 87545, USA.
}

\begin{abstract}
In this article, the development of an electrochemical methane sensor is presented. The mixed potential based sensor is based on tin doped indium oxide (ITO) and platinum electrodes and yttria-stabilized zirconia (YSZ) electrolyte. The sensor was fabricated using the inexpensive tape-cast method. The sensor responded to methane with a response time of $15 \mathrm{~s}$. The staircase response to methane indicated a $44 \mathrm{mV}$ sensor response to $100 \mathrm{ppm}$ of methane. The sensor response indicated a log-linear relationship with the methane concentration. Upon 500 hrs of sensor testing, a 5\% reduction in methane sensitivity was observed. The cross-sensitivity study on the sensor indicated minimal interference to $\mathrm{NO}, \mathrm{NO}_{2}$, and $\mathrm{CO}_{2}$. To improve the sensitivity to methane, a signal conditioning method referred to as the pulsed discharge technique (PDT) was applied. A fourfold increase in methane sensitivity was observed when the sensor was subjected to PDT. Future studies include the miniaturization of the sensor with integrated heater design.
\end{abstract}

Keywords: Methane, Gas Sensor, YSZ, ITO, Electrochemical, Mixed potential 


\section{Introduction}

Natural gas is the most widely consumed energy source in American homes. It is used for furnaces, water heaters, stoves, fireplaces and clothes dryers. Although, natural gas burns cleaner than coal, uncombusted methane leaks from the piped lines or valves erases some of the carbon advantage that natural gas has over fossil fuels at the point of combustion [1]. When unburned methane escapes into the atmosphere, it is a greenhouse gas 20 times more powerful than carbon dioxide. Further, methane emissions result from leaks and routine venting during the production, processing and transportation of natural gas [2].

Unburned Methane, in general, is very stable. But mixtures of methane and air, with the methane content between 5 and 15\% by volume, are explosive. Hence, methane sensors are required for the detection of natural gas. The clear hazards posed by methane bring urgency to the development of an inexpensive methane sensor that is stable, reliable, highly sensitive, and selective whilst being operable in a wide variety of environmental settings with minimal power requirements and maintenance. Many commercial sensors exist in the market for methane detection [3]. However, they are expensive and prone to contamination by species such as carbon monoxide and water vapor.

Investigators have detected methane using a variety of modalities including changes in resistance, refractive index, cataluminescence, current, and chronoamperometry. A review of methane sensor work from 2011 to 2015 [4-13] has been summarized in table 1. Based on these investigations, it can be speculated that the cost, size, and power for each of these approaches preclude them from widespread deployment in mines, industrial factories, fence-lines or pipelines, homes, and other common environments where methane/natural gas is employed.

To address these shortcomings, new methane-monitoring technology is needed that can perform real-time detection and analysis at low cost employing a miniaturized sensor device. Among the several modalities to detect methane, sensors based on electrochemical transduction have clearly emerged as lead candidates for miniaturization, offering minimal power consumption at a cost practical for mass production and commercialization [14]. Potentiometric electrochemical gas sensors offer a simplistic way to measure methane.

In that category, mixed potential sensors are a class of electrochemical devices that develop a non-Nernstian electromotive force (e.m.f) due to the difference in the kinetics of the redox reactions at each electrode/electrolyte interface upon exposure to various analytes [15]. These sensors rely on the fact that two dissimilar electrodes along with an oxygen-ion conducting electrolyte exhibit different nonequilibrium potentials in the presence of a reducing gas and oxygen. The mixed potential sensor design discussed in this work is unique and possesses several inherent advantages [16, 17]. 
Two of the characteristic features leading to exceptional stability and sensitivity are the minimized electrode-electrolyte interface and stable three-phase interface by materials selection and design. The sensor design used dense electrodes and a porous electrolyte, unlike conventional oxygen sensors. Further, the material selection for the electrodes typically involved one electrode with fast and another with slow $\mathrm{O}_{2}$ reduction kinetics aimed at improving the sensitivity. The salient features of the mixed potential sensor are (a) conducive to commercialization, (b) the low power consumption, (c) compactness to fit into critical areas, (d) simple operation, (e) fast response, and (f) a direct voltage readout circumventing the need for any additional conditioning circuitry. In previous studies [18-21], the mixed potential sensors were investigated for the detection of $\mathrm{H}_{2}$, hydrocarbons, $\mathrm{NO}_{\mathrm{x}}$ and $\mathrm{NH}_{3}$. In this study, sensitive detection of methane is demonstrated along with investigations on cross-sensitivity and long-term stability.

\section{Experimental}

Mixed potential sensors based on 8 mol\% yttria stabilized zirconia (YSZ, Tosoh TZ-8YS, Japan) and dense, metal oxide and metal wire electrodes (ITO, Pt) with preferential selectivity to methane were fabricated using a tape cast approach. The YSZ electrolyte powder was dried in air at $100-150{ }^{\circ} \mathrm{C}$ for approximately one hour. The dried powder was mixed with solvents xylene, ethyl alcohol and fish oil (Blown Menhaden) and ball milled for 24 hours. Plasticizers and binders (S-160 butyl benzyl phthalate, polyalkylene glycol and polyvinyl butyral) were then added to this mixture and further ball milled for 24 hours. The mill was then discharged and de-aired for approximately 10 minutes at 20-25 inches of $\mathrm{Hg}$. Prior to casting of the electrolyte slip, pieces of pure Pt wire (0.01” dia) were cut into 1 ” lengths and straightened. A bar-shaped piece of tin-doped indium oxide $\left(90 \% \mathrm{In}_{2} \mathrm{O}_{3} / 10 \% \mathrm{SnO}_{2}\right)$ was cut from a commercial-sourced, dense 2" diameter sputter target (Alpha Aesar) approximately 15 mm x 5 mm x 4 mm using a wet diamond saw. Alternating pairs of ITO and Pt were stuck to tape such that the spacing between the electrode pairs was fixed; each set of ITO/Pt electrode pairs would constitute a single device. After de-gassing, the slurry was cast onto a Si-coated Mylar (G10JRM) carrier film using a standard doctor blade apparatus with a gap of approximately 0.05 ” to 0.2 ”.

Once the tape was cast, it was allowed to partially dry (approximately several minutes). This resulted in a tape that was dry on the outside (facing air) and still very wet on the inside (in contact with the carrier film). This tape was then turned upside down manually so as to expose the wet side to air while the dry side was in contact with the carrier film. The pre-fabricated electrode pairs were then placed on top of this wet tape such that a length of approximately $5 \mathrm{~mm}$ of each electrode was embedded in the electrolyte. The tape was folded on to itself order to enclose the electrodes within the electrolyte. The 
remaining portion of the wires were left exposed to air, uncovered, and would eventually serve as both electrode and signal-out lead wired to be attached to the data acquisition system.

This electrolyte tape with the partially enclosed electrodes is then allowed to air dry fully to form the mechanically stable, green sensor body. Individual sensors were cut from the green tape using a razor. Figure 1 shows the sensor in its green body with ITO and Pt as the electrodes and YSZ as the electrolyte. The tape used to fix the electrode gap and to facilitate handling during the sensor forming procedure was then removed and the sensor green bodies were placed into alumina boat and transferred to a tube furnace for removal of the organics and sintering applying a multistep, temperature profile in air. The sensors were kept at $300^{\circ} \mathrm{C}$ for 45 minutes, then $650^{\circ} \mathrm{C}$ for $1 \mathrm{hr}$ and finally $1100^{\circ} \mathrm{C}$ for $3 \mathrm{hrs}$.

After fabrication and sintering the sensor, it was mounted on an alumina rod with Pt leads, which was then placed in a quartz tube and heated in a tube furnace to the desired operating temperature $\left(550{ }^{\circ} \mathrm{C}\right)$. $\mathrm{CH}_{4}$ was used as the analyte whereas $\mathrm{NO}, \mathrm{NO}_{2}, \mathrm{C}_{3} \mathrm{H}_{6}, \mathrm{H}_{2}, \mathrm{CO}$, and $\mathrm{CO}_{2}$ were used for interference testing. In the current study, the flow rate of the various gas mixtures was controlled using an automated Trace Vapor Generator (TVG). TVG was also used to generate varying concentrations of $\mathrm{CH}_{4}$ and other interfering species. The voltage from the sensor was monitored using a Keithley 2400 Source Measure Unit (SMU, detection error $\pm 0.015 \%$ ) with the Pt electrode connected to its positive terminal. The flow rate of the mix gas was adjusted so as to give the appropriate concentration of the sensing gas in the test mixture. Air was used as the base gas (partial pressure of oxygen: 21\%). The total flow rate was maintained at $200 \mathrm{sccm}$. Figure 2 shows a schematic of the experimental set-up. The device sensitivity is defined as the difference in e.m.f. generated upon exposure to the test and base gas respectively.

\section{Results and Discussion}

The scanning electron microscope (SEM) micrographs of the sensor and the electrode/electrolyte interface are shown in supplemental figures 1 and 2. Supplemental figure 1a shows the bar-shaped solid ITO electrode and a wire Pt electrode embedded in the YSZ electrolyte. Supplemental figure 1b shows the Pt/YSZ interface without any undulations or surface degradation. Such interface morphology lends to reproducible sensor response. While supplemental figure 2a shows the dense ITO/YSZ interface, supplemental figure 2b shows a clean YSZ interface between the ITO and Pt electrodes.

Methane is the most difficult hydrocarbon to be electrooxidized. However, with the use of ITO and Pt electrodes at high temperature $\left(550{ }^{\circ} \mathrm{C}\right)$, methane is speculated to be electrooxidized to carbon dioxide and water. Though kinetically slow, the ITO and Pt electrode achieve different steady state redox potentials when exposed to a mixture of $\mathrm{CH}_{4}$ and $\mathrm{O}_{2}$ determined by the kinetic balance of the electrochemical reactions (1) and (2): 


$$
\begin{aligned}
& 0.5 \mathrm{O}_{2}+2 e^{-} \Leftrightarrow \mathrm{O}^{2-} \ldots \ldots \ldots \ldots(1) \\
& \mathrm{CH}_{4}+4 \mathrm{O}^{2-} \Leftrightarrow \mathrm{CO}_{2}+2 \mathrm{H}_{2} \mathrm{O}+8 e^{-}
\end{aligned}
$$

The electrode that favors the second reaction over the first develops a large non-Nernstian potential. However, the non-electrochemical oxidation (heterogeneous catalysis) of $\mathrm{CH}_{4}$ lowers the differential voltage developed between the electrodes signifying the importance of materials selection and localized heating. The authors envision a sensor with integrated heater to reduce heterogeneous catalysis. Figure 3 shows the response of the sensor to a step increase in the concentration of methane. The baseline response corresponds to $0 \mathrm{~V}$. A $44 \mathrm{mV}$ response is recorded upon $100 \mathrm{ppm}$ exposure of methane. An average response time of $15 \mathrm{~s}$ was observed. The staircase response indicates minimal hysteresis with the sensor going to baseline upon switching to air. The experiment was repeated three times. Figure 4 shows the plot of the sensor response and the concentration of methane (error bars shown). A logarithmic trend was observed following equation (3),

$y=0.0211 \log x$.

Where, $\mathrm{y}$ is the sensor response in ' $\mathrm{V}$ ' and $\mathrm{x}$ is the log concentration of methane in 'ppm'.

After initial testing, the sensor was kept in the base gas at an operating temperature of $550{ }^{\circ} \mathrm{C}$. After 100 hrs, the sensor was re-tested for methane response. Figure 5 shows the sensor response to methane after $100 \mathrm{hrs}$. The sensitivity to $75 \mathrm{ppm}$ of methane was found to be $0.042 \mathrm{~V}$ as opposed to 0.04 $\mathrm{V}$ (0 hrs). Further, a $5 \mathrm{mV}$ decrease in the sensor response was found upon exposure to $25 \mathrm{ppm}$ of methane at 100 hours. The slight deviation in the sensor response can be attributed to the microstructural changes at the interface primarily due to ITO re-equilibrating oxygen activity within the bulk to recover from the high sintering temperature. To study the effect of aging, sensor readings were taken at frequent intervals (upto 500 hrs) for a constant methane concentration of 75 ppm. Figure 6 shows the lifetime study of the sensors upto 500 hrs. As seen from the graph, a 14\% decrease in the sensor response was observed in the time range of 100 to 250 hrs. From 250 hrs to 475 hrs, the sensor response re-bounded to $0.042 \mathrm{~V}$ for $75 \mathrm{ppm}$ of methane. Overall, a 5\% decrease in the sensor response was observed for testing upto 500 hrs (in comparison to 0 hrs). Further testing upto $5000 \mathrm{hrs}$ is envisioned in future. To test the suitability of the sensor for field testing, cross-sensitivity test was performed. For interference studies, 100 ppm of gases such as $\mathrm{NO}, \mathrm{NO}_{2}, \mathrm{CO}_{2}, \mathrm{H}_{2}$, $\mathrm{CO}$, and $\mathrm{C}_{3} \mathrm{H}_{6}$ were used as analytes. Figure 7 shows the cross-sensitivity response indicating a strong signal from $100 \mathrm{ppm}$ of $\mathrm{CH}_{4}$. However, the cross interference from $\mathrm{C}_{3} \mathrm{H}_{6}$ was found to be significant, though in the same direction as methane. To improve the sensitivity of methane amidst interference, a signal conditioning method was adopted, referred to as Pulsed Discharge Technique (PDT). 
In the PDT method [22], the sensor is energized through a series of positive and negative pulses of equal magnitude (for finite pulse duration) between the electrodes with discharge phases in between. Further, the onset of the next pulse is separated by a pause duration characterized by the absence of power to the sensor electrodes. The sensor response is extracted from the discharge characteristics, which depend on the type of gas and its concentration. The PDT technique is thought to change the interfacial defect concentration by voltage pulses in the solid electrolyte. Subsequent measurement of the relaxation rate after perturbation in the presence of the target gas gives rise to unique discharge characteristics. The sensor was subjected to PDT with varying pulse amplitude (200 to $500 \mathrm{mV}$ ) and constant pulse duration ( $1 \mathrm{sec}$ ) and pause duration (5 sec). The methane concentration was maintained at $100 \mathrm{ppm}$. Figure 8 shows the methane sensitivity plot as a function of PDT test conditions. In the absence of PDT, the sensitivity to $100 \mathrm{ppm}$ of methane was $44 \mathrm{mV}$. With $500 \mathrm{mV}$ of excitation, the sensitivity shot up to nearly $200 \mathrm{mV}$. A fourfold (approximately) increase in sensitivity was observed when the sensor is subjected to PDT. The sensitivity of the cross-interfering species was unaffected by the application of PDT.

The mechanism of sensitivity enhancement by PDT is speculated as follows: During polarization in oxygen rich atmosphere (on application of PDT), it appears that metastable platinum oxide (PtO2+) is formed at the Platinum electrode's triple phase boundary (the portion of the electrode where it is in contact with the zirconia substrate and the exhaust gas) and reduced by the following pulse with opposite sign at this interface. With increasing pulse duration, more platinum is oxidized. Therefore, the polarization current of the subsequent pulse grows clearly due to the reduction of the formed oxide and therefore more charge is transferred. The reaction of the $\mathrm{PtO}^{2+}$ with $\mathrm{CH}_{4}$ induces electrochemical promotion of catalysis (EPOC). The theory of platinum oxidation and reduction during alternating polarization and EPOC effect is in good agreement with earlier literature studies [23-25].

Future activities include miniaturization of the sensor using commercial high temperature ceramic co-fire approaches (i.e. screen printing device features on green tape) with integrated heater to fit compact areas and reduce heterogeneous catalysis, improve response time, temperature control and feedback capability, and provide a low-cost avenue to producing an electrochemical sensor with high selectivity and sensitivity to methane.

\section{Conclusions}

The development of a mixed potential based electrochemical methane sensor has been reported. The sensor was made of tin-doped Indium Oxide and Platinum electrodes with Yttria-Stabilized Zirconia as the electrolyte. The staircase response of the sensor indicates minimal hysteresis to methane. A $44 \mathrm{mV}$ response is recorded upon 100 ppm exposure of methane. An average response time of $15 \mathrm{~s}$ was observed. 
A 5\% decrease in methane sensitivity was observed over 500 hrs of sensor testing. The cross-sensitivity study indicated $\mathrm{C}_{3} \mathrm{H}_{6}$ as an interfering species. A fourfold increase in methane sensitivity was observed when the sensor was subjected to PDT. The working principle of PDT still remains unclear, however dynamic changes in the catalytic activity of the electrodes and re-activation of the reaction sites at the electrolyte has been postulated to explain the enhanced sensing attributes. The ceramic, mixed potential sensor approach explored in this work is based on a durable and low cost platform that may easily be manufactured in large numbers and, using the ITO working electrode together with PDT, offers superior sensitivity and lower detection limits compared to other technologies (table 1) surveyed in this work.

\section{Acknowledgements}

This material is based upon work by the National Science Foundation under Grant No. 1503634.

\section{References}

[1] R.W.Howarth, A bridge to nowhere: methane emissions and the greenhouse gas footprint of natural gas, Energy Science and Engineering (2014) 1-14.

[2] https://www.edf.org/sites/default/files/methaneLeakageFactsheet.pdf

[3] W.Eugster and G.W.Kling, Performance of a low-cost methane sensor for ambient concentration measurements in preliminary studies, Atmos.Meas.Tech. 2 (2012) 1925-1934.

[4] S.Roy, C.K.Sarkar, and P.Bhattacharyya, A highly sensitive methane sensor with nickel alloy microheater on micromachined Si substrate, Solid-State Electronics 76 (2012) 84-90.

[5] C.Tao, X.Li, J.Yang, and Y.Shi, Optical fiber sensing element based on luminescence quenching of silica nanowires modified with cryptophane-A for the detection of methane, Sens. And Act. B 156 (2011) 553-558.

[6] A.K.Prasad, S.Amirthapandian, S.Dhara, S.Dash, N.Murali, A.K.Tyagi, Novel single phase vanadium dioxide nanostructured films for methane sensing near room temperature, Sens. And Act. B 191 (2014) 252-256.

[7] Y-n.Zhang, Y.Zhao, and Q.Wang, Measurement of methane concentration with cryptophane Einfiltrated photonic crystal microcavity, Sens. And Act. B 209 (2015) 431-437.

[8] A.Biaggi-Labiosa, F.Sola, M.Lebron-Colon, L.J.Evans, J.C.Xu, G.W.Hunter, G.M.Berger, and J.M.Gonzalez, A novel methane sensor based on porous $\mathrm{SnO}_{2}$ nanorods: room temperature to high temperature detection, Nanotechnology 23 (2012) 455501-455509.

[9] Z.Wu, X.Chen, S.Zhu, Z.Zhou, Y.Yao, W.Quan, and B.Liu, Room Temperature Methane Sensor Based on Graphene Nanosheets/Polyaniline Nanocomposite Thin Film, IEEE Sensors 13 (2013) 777-782. [10] G.Gong and H.Zhu, Development of highly sensitive sensor system for methane utilizing cataluminescence, Luminescence (2015) 1-7. 
Praveen Sekhar, Washington State University Vancouver

[11] Z.Wang, M.Guo, G.A.Baker, J.R.Stetter, L.Lin, A.J.Mason, and X.Zeng, Methane-oxygen electrochemical coupling in an ionic liquid: a robust sensor for simultaneous quantification, Analyst 139 (2014) 5140-5147.

[12] D.Haridas, and V.Gupta, Enhanced response characteristics of $\mathrm{SnO}_{2}$ thin film based sensors loaded with Pd clusters for methane detection, Sens. And Act. B 166-167 (2012) 156-164.

[13] N.M.Vuong, N.M.Hieu, H.N.Hieu, H.Yi, D.kim, Y-S. Han, and M.Kim, $\mathrm{Ni}_{2} \mathrm{O}_{3}$-decorated $\mathrm{SnO}_{2}$ particulate films for methane gas sensors, Sens. And Act. B 192 (2014) 327-333.

[14] E.Bakker, Electrochemical Sensors, Anal.Chem. 76 (2004) 3285-3298.

[15] N.Miura, G.Lu, and N.Yamazoe, Progress in mixed-potential type devices based on solid electrolyte for sensing redox gases, Solid State Ionics 136-137 (2000) 533-542.

[16] R. Mukundan, E.L. Brosha, F.H. Garzon, US Patent \# 7,214,333 (2007).

[17] R. Mukundan, E.L. Brosha, F.H. Garzon, US Patent \# 6,656,336 (2003).

[18] Z.Tang, X.Li, J.Yang, J.Yu, J.Wang, and Z.Tang, Mixed potential hydrogen sensor using $\mathrm{ZnWO}_{4}$ sensing electrode, Sens. And Act. B 195 (2014) 520-525.

[19] G.Hagen, K.Burger, S.Wiegartner, D.Schonauer-Kamin, and R.Moos, A mixed potential based sensor that measures directly catalyst conversion - A novel approach for catalyst on-board diagnostics, Sens. And Act. B 217 (2015) 158-164.

[20] G.Lu, Q.Diao, C.Yin, S.Yang, Y.Guan, X.Cheng, and X.Liang, High performance mixed potential type $\mathrm{NO}_{\mathrm{x}}$ sensor based on stabilized Zirconia and Oxide electrode, Solid State Ionics 262 (2014), 292297.

[21] I.Lee, B.Jung, J.Park, C.Lee, J.Hwang, and C.O.Park, Mixed potential $\mathrm{NH}_{3}$ sensor with $\mathrm{LaCoO}_{3}$ reference electrode, Sens. And Act. B 176 (2013) 966-970.

[22] B.Farber, Method of sensor conditioning for improving signal output stability for mixed gas measurements, US Patent \#7585402 (2009).

[23] S.Fischer, R.Pohle, E.Magori, D.Schonauer-Kamin, M.Fleischer, and R.Moos, Pulsed polarization of platinum electrodes on YSZ, Solid State Ionics 225 (2012) 371-375.

[24] G.Foti, Charge storage at Pt/YSZ interface as the origin of 'permanent' electrochemical promotion of catalysis, Periodica Polytechnica-Chemical Engineering 53(2009) 41-47.

[25]S.Fischer, R.Pohle, B.Farber, R.Proc, J.Kaniuk, M.Fleischer, and R.Moos, Method for detection of NOx in exhaust gases by pulsed discharge measurements using standard zirconia-based lambda sensors, Sens. And Act. B 147 (2010) 780-785. 
Praveen Sekhar, Washington State University Vancouver

\section{Figure Captions}

Figure 1. ITO/YSZ/Pt tape cast sensor in its green body form. ITO serves as the working electrode and Pt as pseudocounter electrode.

Figure 2. Schematic of the experimental set-up.

Figure 3. Staircase response of the sensor to various concentrations (indicated) of methane.

Figure 4. Concentration curve - Sensor response as function of methane concentration.

Figure 5. Sensor response to $25 \mathrm{ppm}$ and $75 \mathrm{ppm}$ of methane after $100 \mathrm{hrs}$ of testing.

Figure 6. Long-term testing: Sensor testing (in sampling intervals of approximately 50hrs) over 500 hrs for 75 ppm of methane.

Figure 7. Cross-Sensitivity study using different analytes (all gases 100ppm concentration in air).

Figure 8. Methane sensitivity (100 ppm) as a function of PDT pulse amplitude.

Supplemental Figure 1. Scanning Electron Microscope Images of the Sensor

Supplemental Figure 2. Scanning Electron Microscope Images of the Clean Interface

\section{Table Caption}

Table 1. A review of methane sensor research from 2011 to 2015 
Table 1. A review of methane sensor research from 2011 to 2015

\begin{tabular}{|c|c|c|c|c|}
\hline Author & Sensing Platform & Mode of Detection & $\begin{array}{l}\text { Operating } \\
\text { Temperature } \\
\left({ }^{0} \mathrm{C}\right)\end{array}$ & $\begin{array}{l}\text { Lower } \\
\text { Detection } \\
\text { Limit (ppm) }\end{array}$ \\
\hline $\begin{array}{l}\text { Roy et.al (2012) } \\
\text { [4] }\end{array}$ & $\begin{array}{l}\text { Nanostructured } \\
\mathrm{ZnO} \text { with } \mathrm{Ni} \text { alloy } \\
\text { heater }\end{array}$ & Resistance change & 200 & 100 \\
\hline $\begin{array}{l}\text { Tao et.al (2011) } \\
\text { [5] }\end{array}$ & $\begin{array}{l}\text { Silica nanowires } \\
\text { modified with } \\
\text { Crytophane-A } \\
\text { molecule }\end{array}$ & $\begin{array}{l}\text { Luminescence } \\
\text { quenching }\end{array}$ & $\begin{array}{l}\text { Room } \\
\text { temperature }\end{array}$ & 100 \\
\hline $\begin{array}{l}\text { Prasad et. } \mathrm{Al} \\
(2014) \text { [6] }\end{array}$ & $\begin{array}{l}\mathrm{VO}_{2} \\
\text { nanostructured } \\
\text { films } \\
\end{array}$ & Resistance change & 50 & 50 \\
\hline $\begin{array}{l}\text { Zhang et.al } \\
(2015) \\
{[7]}\end{array}$ & $\begin{array}{l}\text { Cryptophane-E } \\
\text { infiltrated Photonic } \\
\text { Crystal } \\
\text { Microcavity }\end{array}$ & $\begin{array}{l}\text { Change in refractive } \\
\text { index }\end{array}$ & $\begin{array}{l}\text { Room } \\
\text { temperature }\end{array}$ & 700 \\
\hline $\begin{array}{l}\text { Biaggi-Labiosa } \\
\text { et. Al (2012) [8] }\end{array}$ & $\begin{array}{l}\text { Porous tin oxide } \\
\text { nanosrods }\end{array}$ & Resistance change & 500 & 2500 \\
\hline $\begin{array}{l}\text { Wu et.al (2013) } \\
\text { [9] }\end{array}$ & $\begin{array}{l}\text { Graphene-PANI } \\
\text { nanocomposite }\end{array}$ & Resistance change & $\begin{array}{l}\text { Room } \\
\text { temperature }\end{array}$ & 10 \\
\hline $\begin{array}{l}\text { Gong et. al } \\
(2015) \\
{[10]}\end{array}$ & $\begin{array}{l}\mathrm{SnO}_{2} / \mathrm{TiO}_{2} \\
\text { nanoparticles }\end{array}$ & Cataluminescence & $\begin{array}{l}\text { Room } \\
\text { temperature }\end{array}$ & 10 \\
\hline $\begin{array}{ll}\text { Wang } & \text { et.al } \\
(2014) & \\
{[11]} & \end{array}$ & $\begin{array}{ll}\text { Pt/Ionic } & \text { liquid } \\
\text { electrolyte } & \end{array}$ & Current density & $\begin{array}{l}\text { Room } \\
\text { temperature }\end{array}$ & 3000 \\
\hline $\begin{array}{ll}\text { Haridas } & \text { et.al } \\
(2012)[12] & \\
\end{array}$ & $\begin{array}{l}\mathrm{SnO}_{2} \text { thin film - } \\
\text { Pd cluster }\end{array}$ & Resistance change & 220 & 200 \\
\hline $\begin{array}{l}\text { Vuong et. al } \\
\text { (2014) [13] }\end{array}$ & $\begin{array}{l}\text { Ni2O3 decorated } \\
\text { SnO2 thin-film }\end{array}$ & Resistance change & 400 & 200 \\
\hline
\end{tabular}




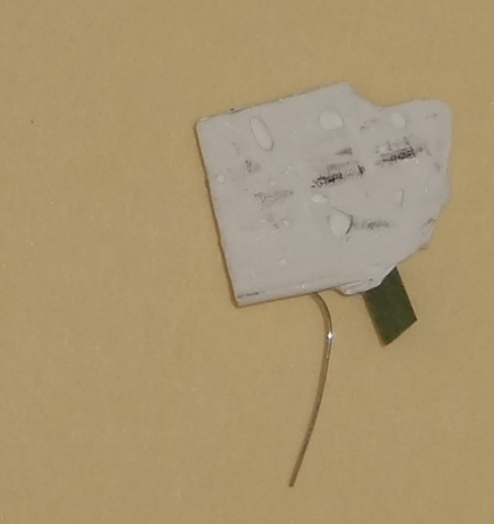

Figure 1

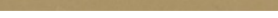

$$
1
$$$$
\text { L }
$$
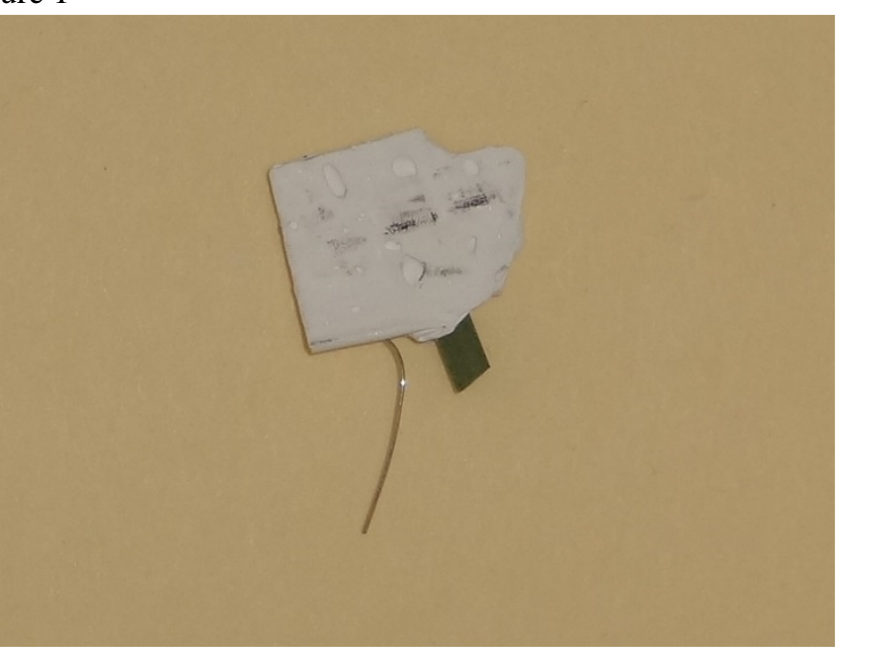

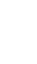




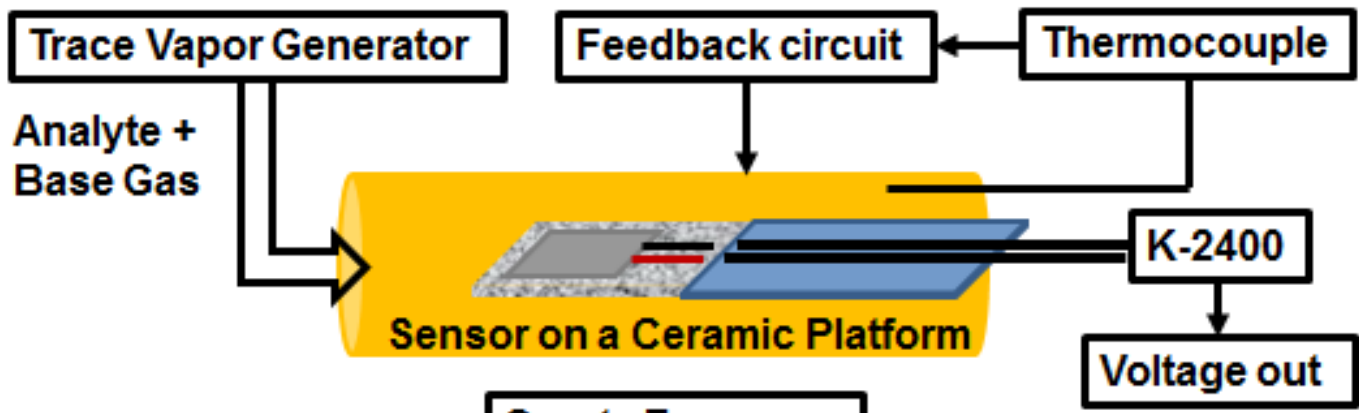

Quartz Furnace 
Figure 3

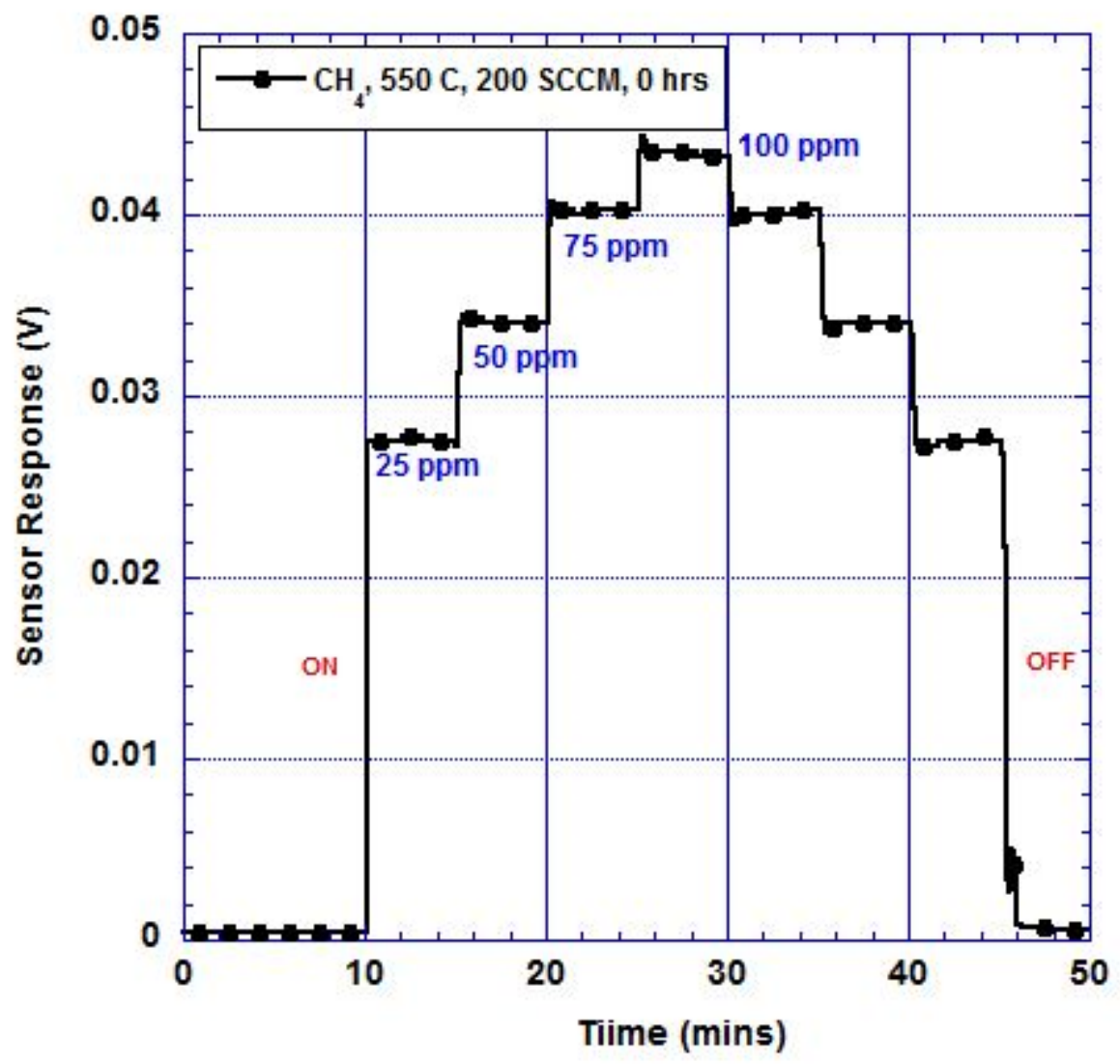


Figure 4

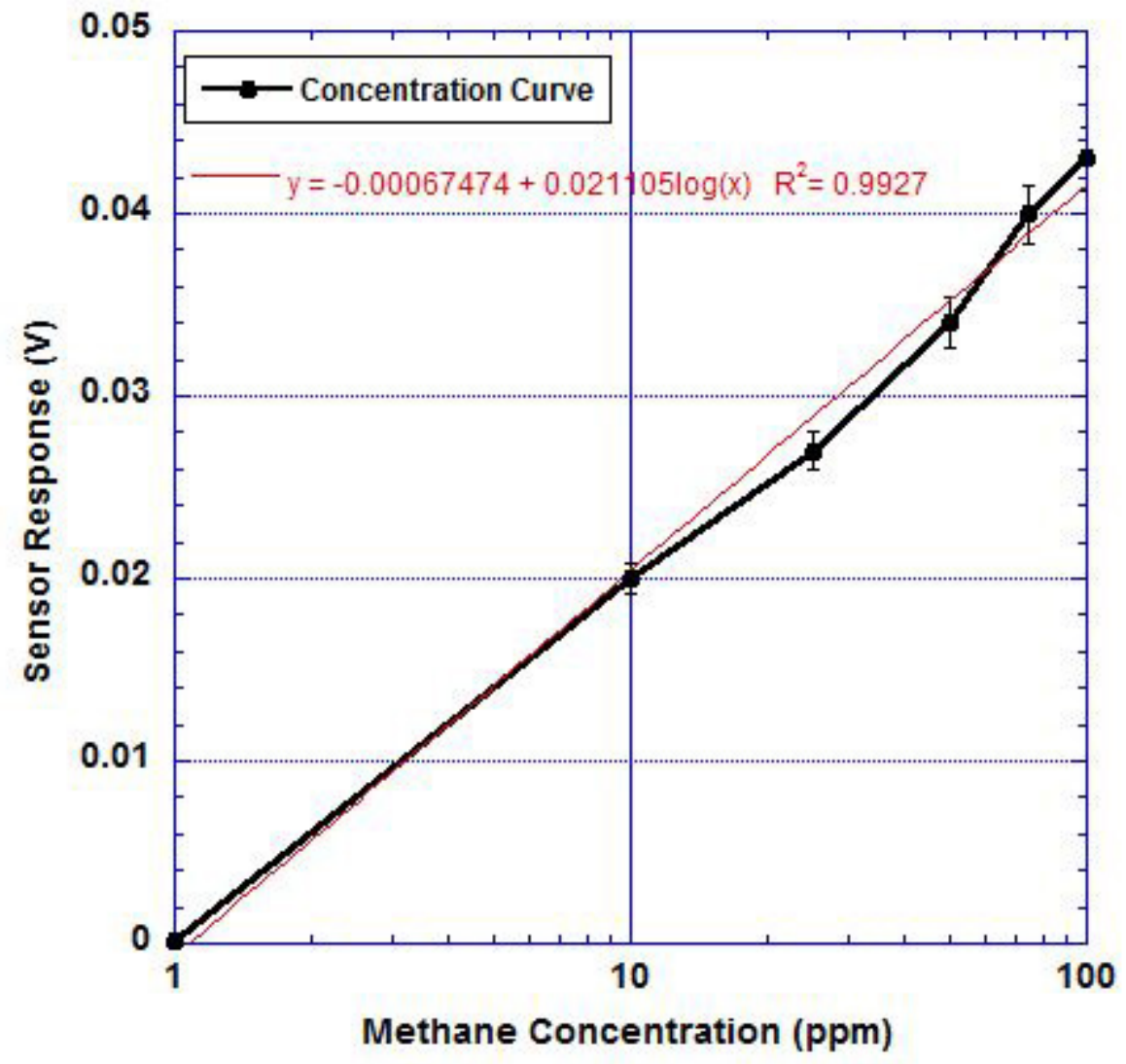


Figure 5

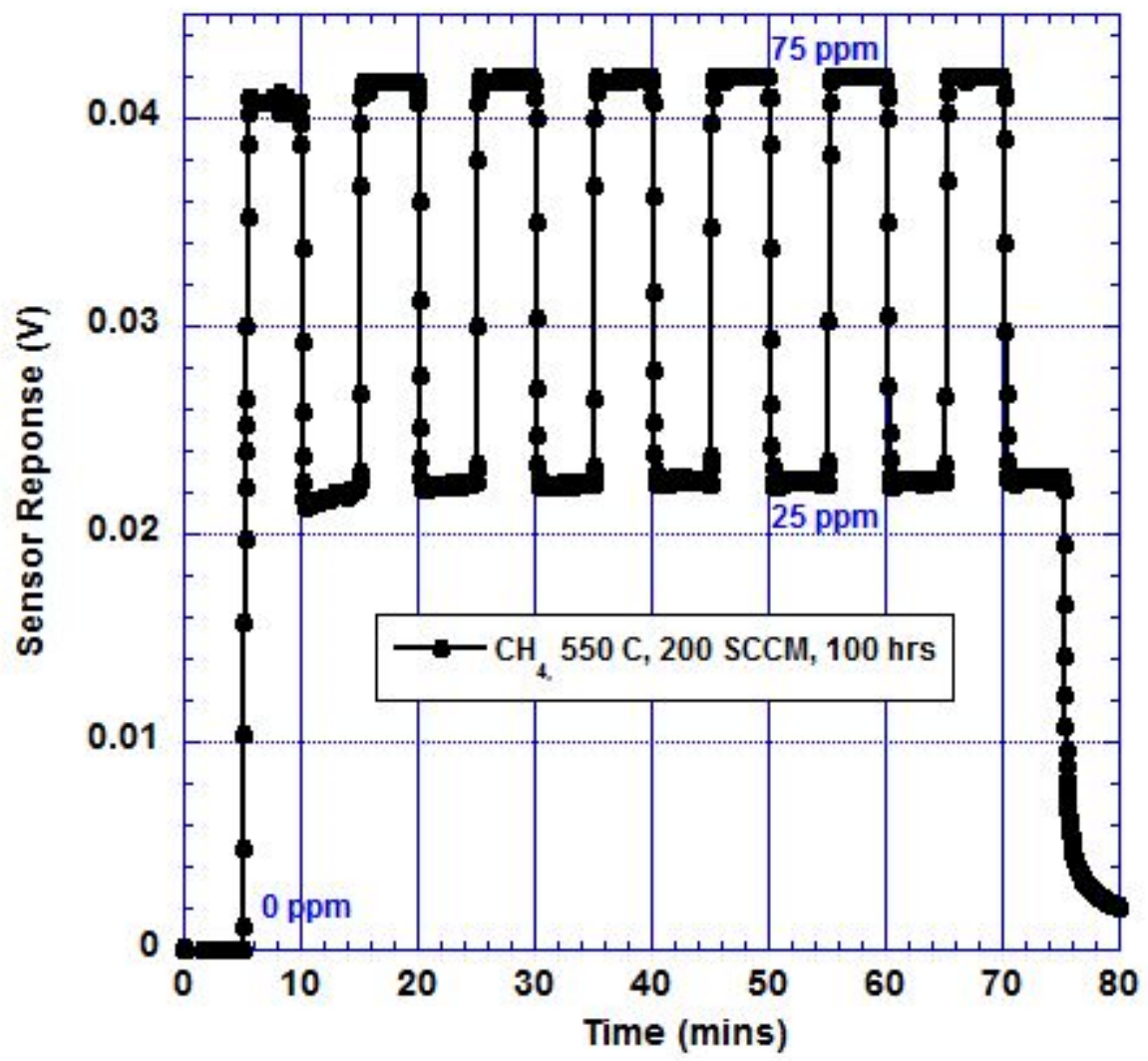




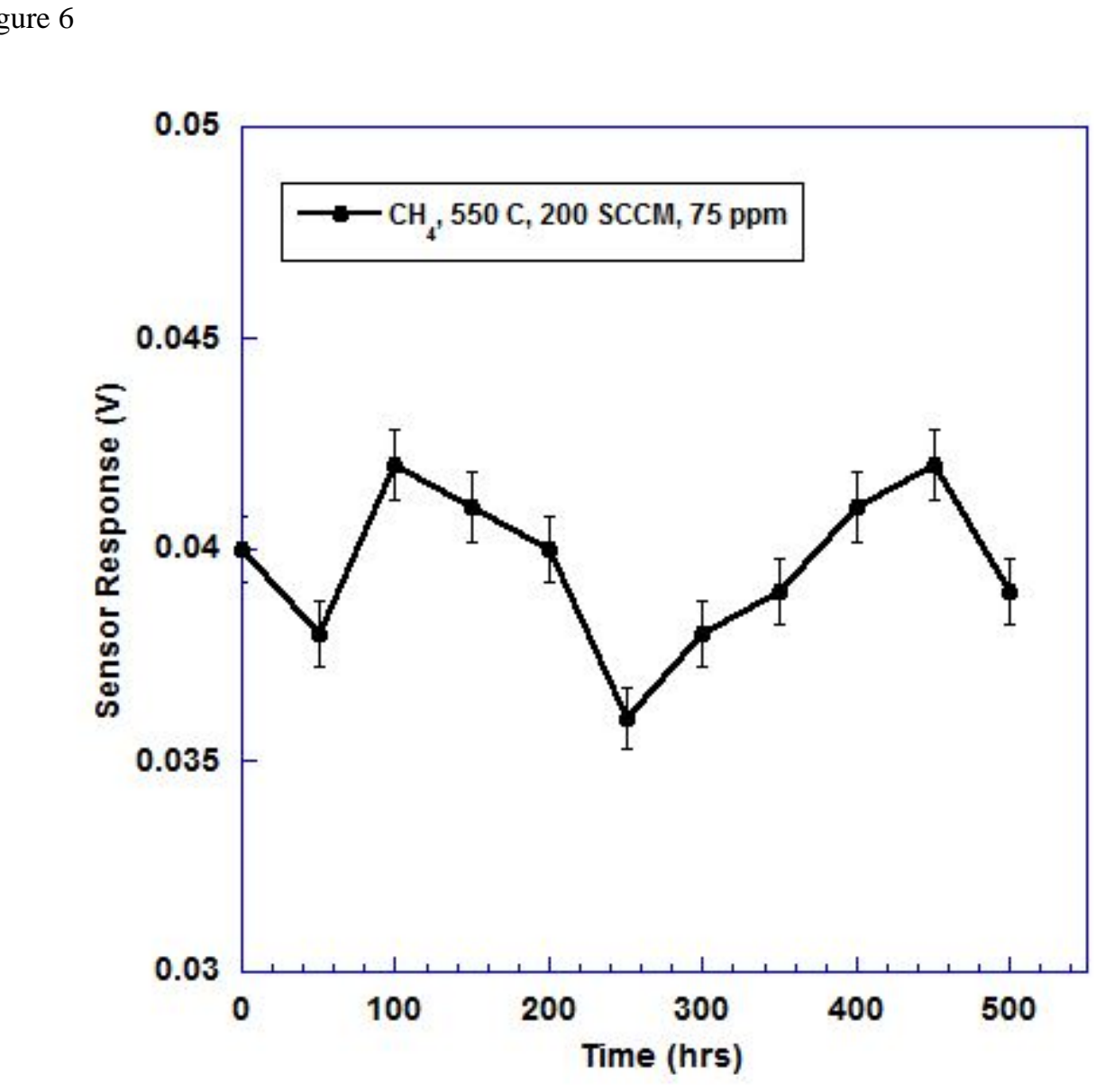

Figure 6

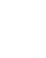

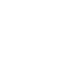




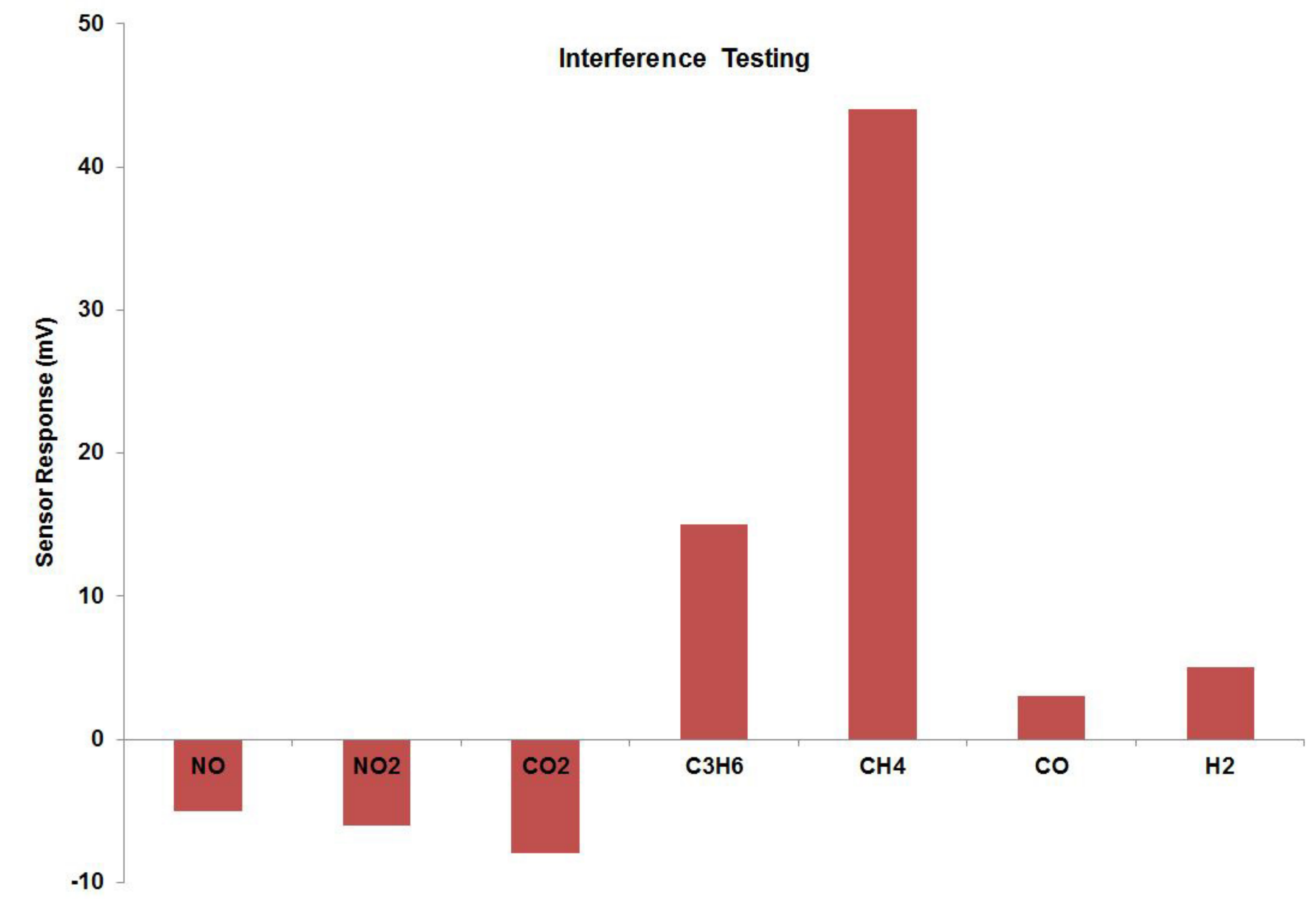


Figure 8

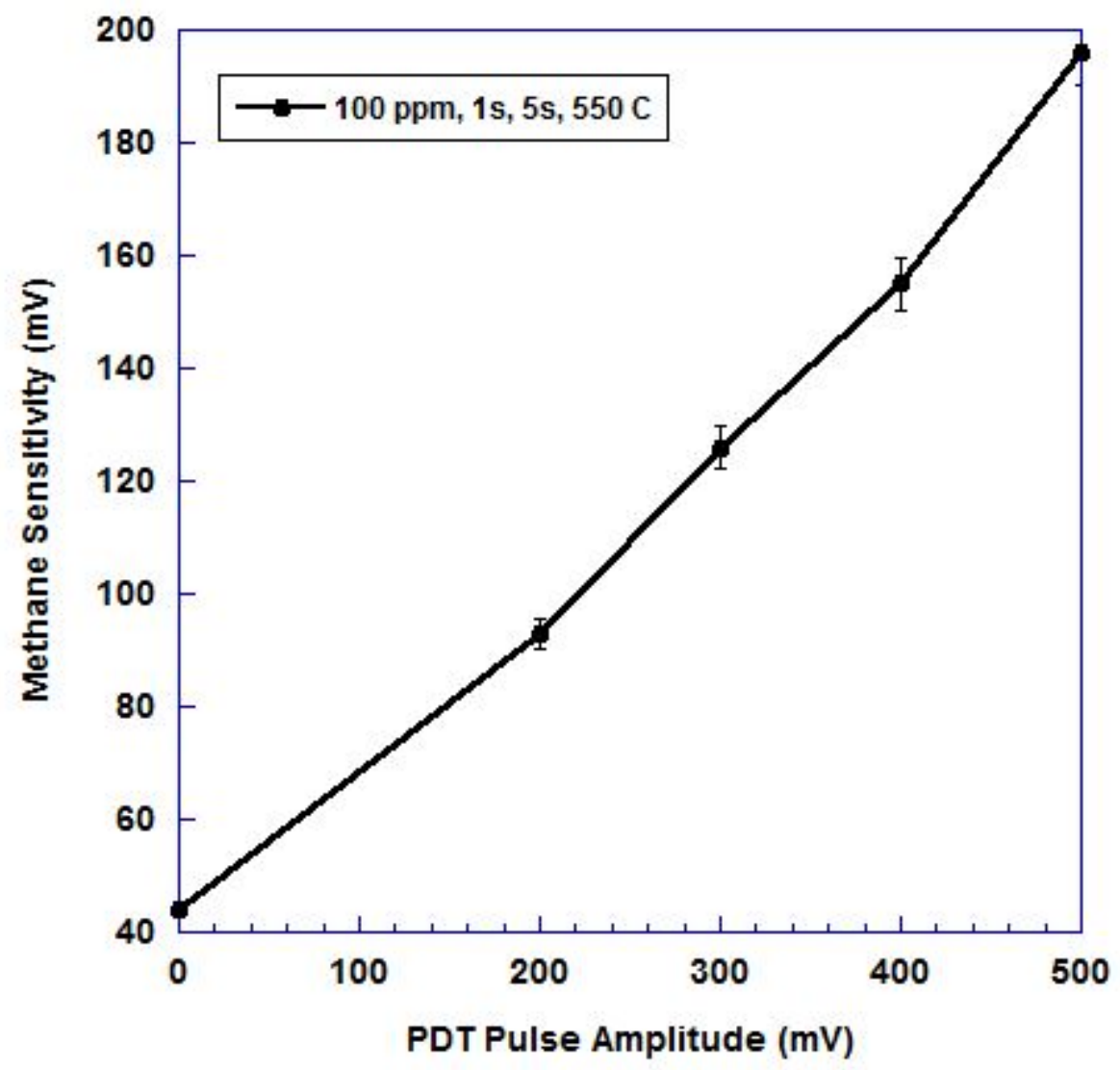




\section{Author Biographies}

Praveen Kumar Sekhar received the B.E. (Hons.) degree from the Coimbatore Institute of Technology, Coimbatore, India, in 2001, and the master's and Ph.D. degrees in electrical engineering from the University of South Florida, Tampa, FL, USA, in 2005 and 2008, respectively. He has been an Assistant Professor with the School of Engineering and Computer Science, Washington State University, Vancouver, WA, USA, since 2011. He was a Post-Doctoral Research Associate with the Division of Materials Physics and Applications, Los Alamos National Laboratory, Los Alamos, NM, USA, for two years. His dissertation focused on the synthesis, characterization, and applications of silica nanowires received the Outstanding Dissertation Award. His current research interests include the development of electrochemical gas sensors and biosensors in addition to materials science and characterization, impedance spectroscopy, microfabrication, and applied statistics.

Eric L. Brosha received the B.A. (summa cum laude) degree in physics from Rider College, Lawrenceville, NJ, USA, in 1989. He was a recipient of the Ashton Fellowship from the University of Pennsylvania, Philadelphia, PA, USA, in 1989, where he received the Ph.D. degree in materials engineering in 1993. He is currently a staff member with the Division of Materials Physics and Applications, Los Alamos National Laboratory, Los Alamos, NM, USA. His current research interests include synthesis of PEM fuel cell catalysts, electrochemical gas sensors, materials chemistry and electrochemistry of high temperature solid-oxide fuel cell electrolyte and electrode materials, X-ray, diffraction, X-ray fluorescence spectroscopy, and thermal analysis of materials.

Cortney Kreller received her B.S. in Chemical Engineering from the University of Maryland, Baltimore County in 2004. She received her Ph.D. in Chemical Engineering from the University of Washington in 2011. Dr. Kreller is currently a staff scientist in the Materials Physics and Applications division at Los Alamos National Laboratory. Her research interests include electrochemical sensors, fuel cells, and electrosynthesis of fuels. 